\title{
Mediastinal Benign Mature Teratoma in Young Girl, Catastrophic Delayed and Complications of Surgery: A Case Report
}

\author{
Ketut Putu Yasa ${ }^{1 \star}$, A. A. Christ Tedy Permana ${ }^{2}$, Sri Mahendra Dewi ${ }^{3}$ \\ ${ }^{1}$ Cardiothoracic Vascular and Endovascular Division, Department of Surgery, Udayana University, Sanglah Hospital, Denpasar, \\ Bali, Indonesia; ${ }^{2}$ General Surgery Training Program, Department of Surgery, Udayana University, Sanglah Hospital, Denpasar, \\ Bali, Indonesia; ${ }^{3}$ Department of Pathology, Udayana University, Sanglah Hospital, Denpasar, Bali, Indonesia
}

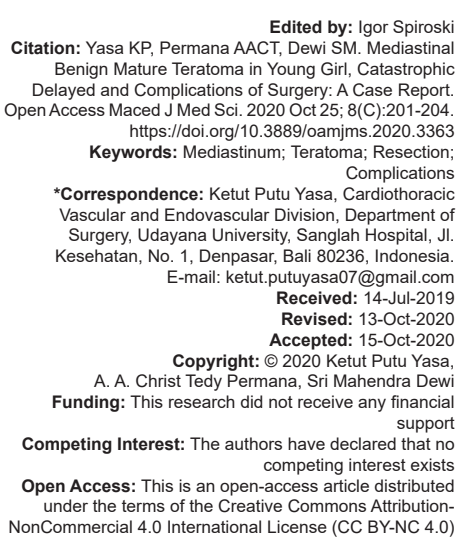

Edited by: Igor Spirosk Citation: Yasa KP, Permana AACT, Dewi SM. Mediastina Benign Mature Teratoma in Young Girl, Catastrophic Delayed and Complications of Surgery: A Case Report.
Open Access Maced J Med Sci. 2020 Oct 25; 8(C):201-204. https://doi.org/10.3889/oamjms.2020.3363 Keywords: Mediastinum; Teratoma; Resection; *Correspondence: Ketut Putu Yasa, Cardiothoracic Vascular and Endovascular Division, Department of Surgery, Udayana University, Sanglah Hospital, Jl. Kesehatan, No. 1, Denpasar, Bali 80236, Indonesia. E-mail: ketut.putuyasa07@gmail.com Received: 14-Jul-2019 Revised: 13-Oct-2020 Accepted: 15 -Oct-2020 A. A. Christ Tedy Permana Sri Matu Yasa A. A. Christ Tedy Permana, Sri Mahendra Dew rencion Competing Interest: The authors have declared that no Open Access: This is an open-access article distributed under the terms of the Creative Commons AttributionNonCommercial 4.0 International License (CC BY-NC 4.0)

\section{Abstract}

BACKGROUND: Teratomas are the most common of germ cell tumor and have different epidemiology, histology, and biology than the others. These tumors occur equally in men and women are generally benign, occur in the mediastinum and compromise approximately $20 \%$ of anterior mediastinal masses. All forms of these tumors have a peak incidence in young adults.

CASE REPORT: A huge mediastinal teratoma present in young girl 15 years old, a tumor located in the right chest with mass compression effect to spine, heart, and lung, produce prolong symptoms of dyspnea and chest pain Delayed clinical presentation influences to post-operative complications such as prolong atelectasis, rupture of tumor mass which spoiled of tumor contents, empyema, and sepsis.

CONCLUSION: Mediastinal mature teratoma with the delayed clinical presentation will give technical difficulties for resection and increase the risk of post-operative complications.

\section{Introduction}

Mediastinal teratomas are thought to be the result of pluripotent germ cell that fails to migrate from mediastinum to the gonads during early development. These tumors occur equally in men and women, are generally benign, and consist of at least two of the three embryologic layers: Endoderm, mesoderm, and ectoderm [1]. Teratoma may be mature, well-differentiated, poorly differentiated, immature, or with malignant transformation [2]. A mature teratoma has differentiated into mature somatic structure such as skin, bone, teeth, fat, and epithelial tissue. Most of the symptoms are a result of compression of nearby structures. Treatment of choice for mediastinal teratoma is complete surgical resection [1].

\section{Case Presentation}

Young girl 15 years old with chief complain shortness of breath in the past 4 years ago. Shortness of breath felt burdensome in the last 1 month ago; sometimes, the right chest feels painful. Patients fells that her body weight was decreased, and body weight loss was around $5 \mathrm{Kg}$ during last 3 months. Patients with a history of control to cardiothoracic out-patient clinic and already diagnosed with tumor mediastinum 1 year ago, and then plans for surgical removal of the tumor were carried out, but the patient and family refused.

On physical examination, there was bulging on the right chest with no breath sound on the right lung, slight dilatation of chest superficial vein, but no edema on the face and upper extremities (Figure 1). Chest plain X-ray (Figure 2) and computed tomography scan (Figure 3 ) revealed huge cystic well-defined mass shadow with signs of calcification in the right chest with mass compression effect to spine, heart, and lung. Laboratory findings for tumor marker beta-human chorionic gonadotropin ( $\beta \mathrm{HCG}$ ) and alpha-fetoprotein (AFP) were normal limit, another laboratory test was normal. Pre-operative clinical diagnosis of suspect mediastinal teratoma was entertained. The patient underwent complete surgical excision of a mediastinal tumor through right posterior lateral thoracotomy.

Intra-operative findings, there was huge solid 


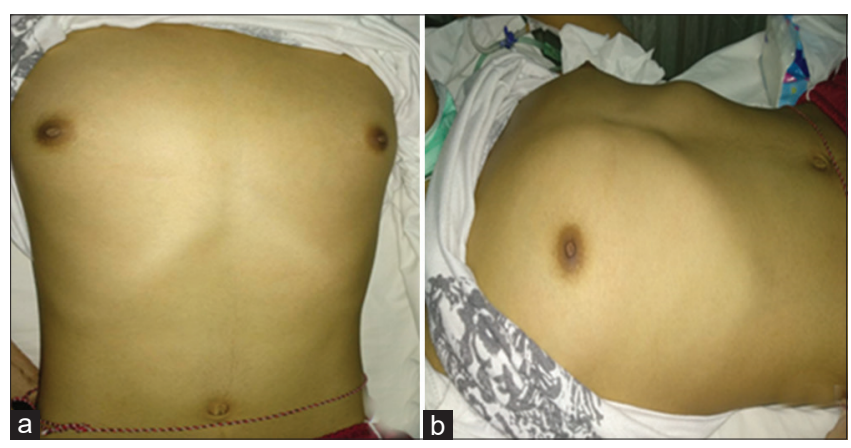

Figure 1: Clinical picture showing bulging of the right chest, anterior view (a) and lateral view (b), accompanied by slight dilatation of superficial veins

cystic mass fulfill entire of right pleural space, and there was persistent atelectasis, rupture on some area of cystic mass during difficult dissection with spoiled tumor contents material to the operation field (Figure 4a). The complete excised mass consisted of mature squamous

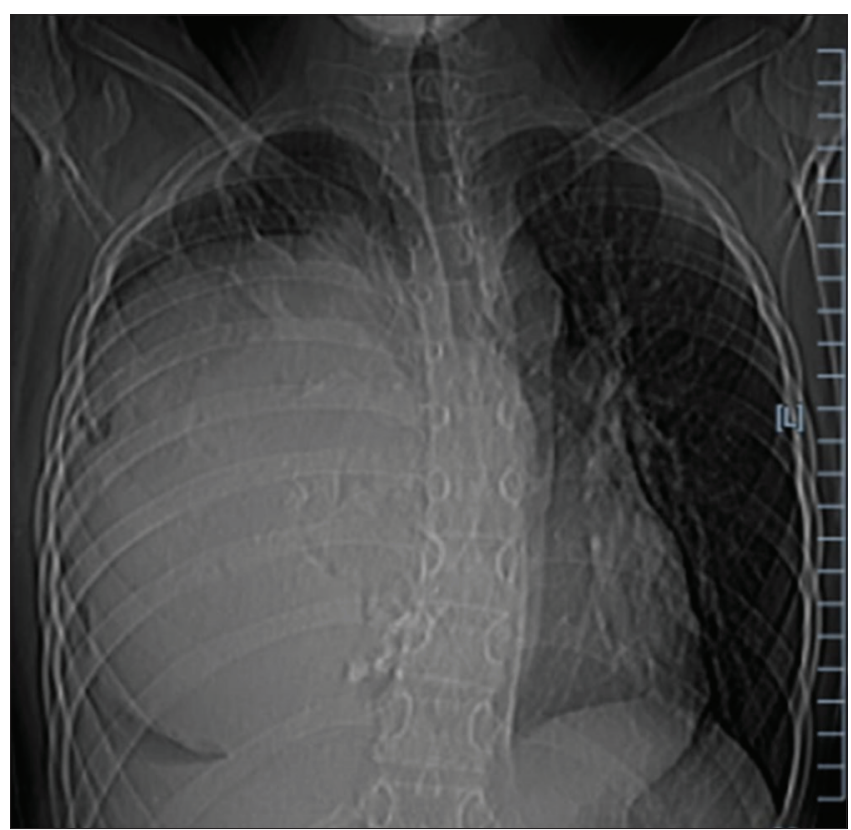

Figure 2: Chest $X$-ray showing huge rounded well-defined mass shadow in the right chest with mass compression effect to right bronchus (atelectasis) and spine (scoliosis)

epithelium (skin), salivary gland, hair, mature fat tissue, mature cartilage, and mature respiratory epithelium (Figure 4b). Histopathologic examination confirmed the diagnosis of benign mature teratoma (Figure $5 a$ and $b$ ). Post-operative the patient has complications such

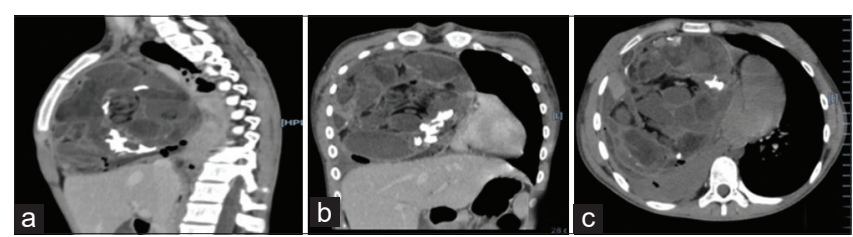

Figure 3: Computed tomography scan in coronal (a), sagittal (b), and axial (c) view showing huge cystic well-defined mass shadow with signs of calcification in the right chest with mass compression effect to spine, heart, and lung

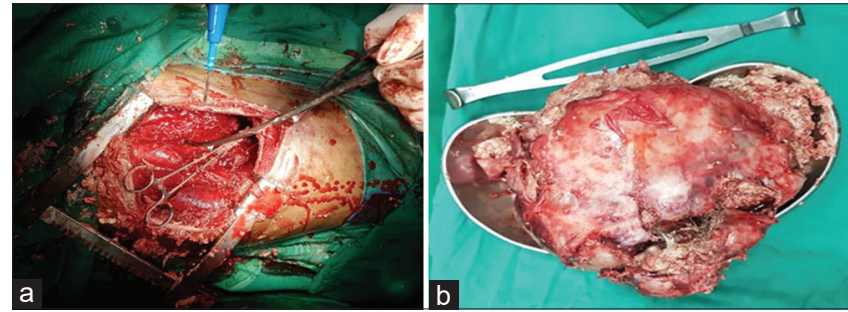

Figure 4: Intraoperative finding through right posterolateral thoracotomy approach, rupture of the solid cystic mass layer with sebaceous component spoiled operation field (a). Complete resection of huge anterior mediastinal tumor with rupture of the solid cystic layer. Soft tissue, fat, hair, and bone are components of mass (b)

as persistent atelectasis on chest X-ray (Figure 6a), with prolonging intubation, empyema, and surgical site infection as wound dehiscence (Figure 6b).

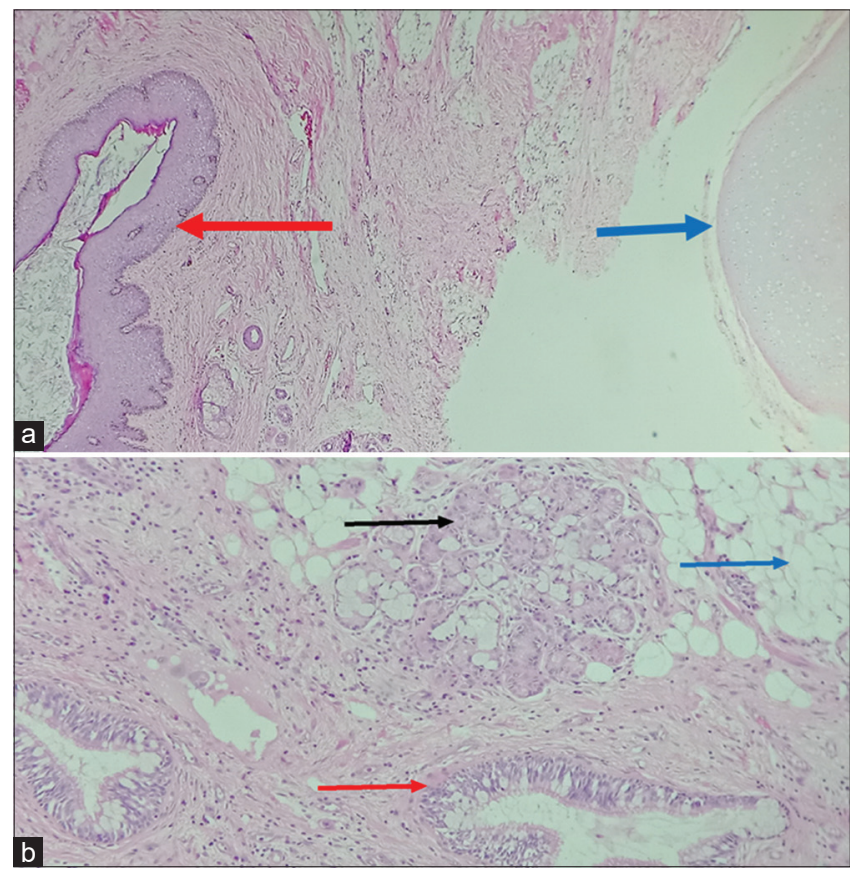

Figure 5: Histopathologic examination. Plate A; Red arrow: Stratified squamous epithelium (skin); Blue arrow: Mature cartilage. Plate B; Black arrow: Salivary gland; Red arrow: Respiratory, epithelium; Blue arrow: Mature fat tissue

Re-debridement of wound dehiscence and open drainage of empyema was done. The wound was well treated and there is no dehiscence, but unfortunately, the patient was passed away cause of sepsis on day- 9 of surgery.

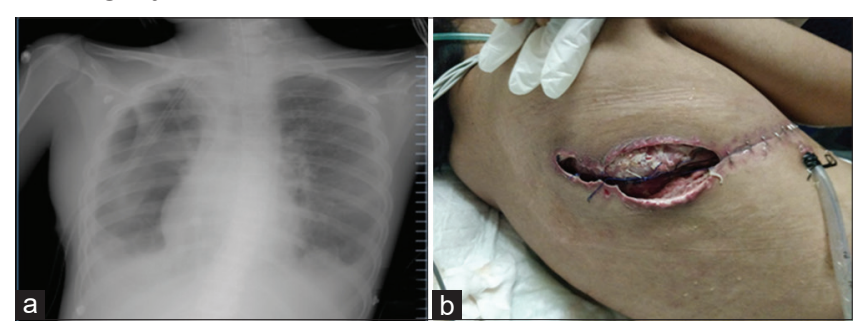

Figure 6: Chest X-ray post-tumor resection: Persistent atelectasis, lung collapse, and empyema (a). Wound dehiscence on site of right posterolateral thoracotomy and empyema as complications after tumor resection (b) 


\section{Discussion}

Mediastinal mature teratoma is uncommon. However, teratomas are the most common form of germ cell tumor (GCTs) and have different epidemiology, histology, and biology than the others. These tumors occur equally in men and women, are generally benign [1]. GCTs both seminomas and non-seminoma occur in the mediastinum and compromise approximately 20 percent of anterior mediastinal masses. All forms of these tumors have a peak incidence in young adults. In our case, the patient was a young girl 15 years old; similar to the literature non-seminomas include embryonal carcinoma, teratocarcinoma, choriocarcinoma, yolk sac tumors, and benign teratoma. Teratoma of the mediastinum usually grows slowly [3] that is why patients do not feel any significant complaints for a long period of time, the tumor to become very large, filling the entire thoracic cavity with adhesions to the surrounding organs, this makes it difficult to remove the tumor and risks the cyst rupture. Most of the symptoms are related to compression of nearby structures such as chest pain, dyspnea, cough, or pulmonary infection [4]. In our case, there was prolong symptom of dyspnea as long as 4 years, but patients family refused for surgical resection, therefore, delayed clinical presentation can influence to the post-operative complications such as prolong atelectasis, rupture of tumor mass which spoiled of tumor contents, empyema, and sepsis.

Laboratory findings for tumor marker $\beta$ HCG and AFP were the normal limit, same as other reports. Patients with benign mature mediastinal teratoma, serum $\beta$ HCG, lactate dehydrogenase $(\mathrm{LDH})$, and AFP levels were within the normal range [5]. Benign teratoma (pure mature teratoma) does not secrete AFP and $\beta$ HCG. Serum levels of AFP, $\beta$ HCG, and $\mathrm{LDH}$ are well-validated in their utility as noninvasive diagnostic of GCTs. A significant elevation of serum AFP or B HCG indicates significant components of yolk sac tumor or choriocarcinoma, respectively, and rules out pure mature teratoma or seminoma [6]. During the diagnosis and follow-up of mediastinal teratoma, it is necessary to monitor serum tumor markers AFP and $\beta$-HCG. Elevated serum AFP or $\beta$-HCG level indicates a malignant component to the teratoma such as embryonal carcinoma, endodermal sinus tumor, or choriocarcinoma [7].

Patients with benign mediastinal teratoma have a good prognosis after surgical resection [7]. Complete surgical excision is the treatment of choice because of probable complications such as compression of adjacent structures, rupture, or malignant transformation [8]. Complete excision of mediastinal teratoma usually performed through median sternotomy [9] or thoracotomy [10] or thoracoscopy [11], however, excision may be difficult because of tumor large size and adherent to adjacent and vital intrathoracic structure. The tumors of relative size are not too large, well-defined lobulated round mass, and there was no definite invasion to nearby structures, complete surgical resection giving good results without complications [6] and recurrence [12]. Otherwise, the tumor is very large, filling almost entire of the thorax cavity which has been adhered to the surrounding organs, there is a risk of damage to surrounding organs [12]. In our case, complete surgical excision was successful, but because of huge tumor size and has been adhered to the surrounding organs, there was complication persistent atelectasis, and rupture on some area of cystic mass during difficult dissection with spoiled tumor contents material to the operation field, put a risk on surgical site infection, empyema, sepsis, and death.

\section{Conclusion}

Mediastinal mature teratoma is uncommon. Delayed clinical presentation will give technical difficulties for resection and increase the risk of postoperative complication such as prolong atelectasis, tumor rupture, surgical site infection, empyema, sepsis, and death.

\section{Authors' Contributions}

KPY [1] conceived the case report, contributed to collection of clinical details and writing, reviewing and finalization of the manuscript; AACTP [2] prepared the first draft besides contribution to collection of clinical details and illustrations; SMD [3] contributed to reviewing pathological specimen and illustration. All authors reviewed and finally approved the final manuscript.

\section{References}

1. Plantmason L, Lui N, Theodore P. Mediastinal disease. In: Yuh DD, Vricella LA, Yang SC, Doty JR, editors. Johns Hopkins Textbook of Cardiothoracic Surgery. $2^{\text {nd }}$ ed. New York: McGrawHill; 2014. p. 229-41.

2. Dhond AP, Agrawal SO, Sirmukaddam SV, Srinath S, Roplekar P, Desai PR. Mediastinal teratoma: A case report with review of literature. J Sci Soc. 2016;43:57-9. https://doi. org/10.4103/0974-5009.175469

3. Agarwal G, Kar DK. Teratoma of the anterior mediastinum presenting as a cystic neck mass: A case report. J Med Case Rep. 2008;2:23. https://doi.org/10.1186/1752-1947-2-23 
PMid:18221571

4. Moeller $\mathrm{KH}$, Rosado-de-Christenson ML, Templeton PA. Mediastinal mature teratoma: Imaging feature. AJR Am J Roentgenol. 1997;169(4):985-90. https://doi.org/10.2214/ ajr.169.4.9308448

PMid:9308448

5. Srivastava P, Srivastava MK, Srivastava S, Roshan S. Excision of benign mature anterior mediastinal teratoma through trapdoor incision: A case report with review of literature. Arch Int Surg. 2015;5:213-6. https://doi.org/10.4103/2278-9596.174667

6. Sandoval JA, Malkas LH, Hickey RJ. Clinical significance of serum biomarkers in pediatric solid mediastinal and abdominal tumors. Int J Mol Sci. 2012;13(1):1126-53. https://doi. org/10.3390/ijms13011126

PMid:22312308

7. Tian Z, Liu H, Li S, Chen Y, Ma D, Han Z, et al. Surgical treatment of benign mediastinal teratoma: Summary of experience of 108 cases. J Cardiothorac Surg. 2020;15:36. https://doi.org/10.1186/ s13019-020-1075-8

PMid:32066478

8. No TH, Seol SH, Seo GW, Kim DI, Yang SY, Jeong CH, et al.
Benign mature teratoma in anterior mediastinum. $\mathrm{J}$ Clin Med Res. 2015;7(9):726-8. https://doi.org/10.14740/jocmr2270w PMid:26251691

9. de Hoyos A, Sundaresan RS. Resection of mediastinal teratoma. Oper Tech Thorac Cardiovasc Surg. 2001;6:209-20. https://doi. org/10.1053/otct.2001.31302

10. Squeff FA, Gerace ES, Saad R Jr., Botter M, Gonçalves R, Paes JF. Mediastinal teratoma with malignant degeneration case report. J Bras Pneumol. 2008;34:631-4. https://doi. org/10.1590/s1806-37132008000800015

PMid: 18797750

11. Pham LH, Trinh DK, Nguyen AV, Nguyen LS, Le DT, Nguyen DH. Thoracoscopic surgery approach to mediastinal mature teratomas: A single center Experience. J Cardiothorac Surg. 2020;15(1):35. https://doi.org/10.1186/s13019-020-1076-7 PMid:32051013

12. Zhao $\mathrm{H}$, Zhu $\mathrm{D}$, Zhou Q. Complete resection of a giant mediastinal teratoma occupying the entire right hemithorax in a 14-year-old boy. BMC Surg. 2014;14:56. https://doi. org/10.1186/1471-2482-14-56

PMid:25151139 